\title{
PRAGMÁTICAS DO PLURIVERSO Uma entrevista com o sociólogo e filósofo Martin Savransky
}

\author{
PRAGMATICS OF THE PLURIVERSE \\ An interview with sociologist and \\ philosopher Martin Savransky
}

Martin Savransky

Goldsmiths College, University of London

Sociology Department | Londres, Inglaterra

m.savransky@gold.ac.uk | ORCID iD: 0000-0002-0807-8350

Thiago Pinho

Universidade Federal da Bahia

Programa de Pós-Graduação em Ciências Sociais | Salvador, Bahia pinho.thiago@hotmail.com | ORCID iD: 0000-0003-4147-6331

$\mathrm{M}$

artin Savransky é professor adjunto no departamento de Sociologia da Goldsmiths college (Universidade de Londres), local em coordena o Mestrado em Ecologia, Cultura e Sociedade. Ele trabalha na interseção com a filosofia, estudos pós-coloniais e ecologia política. Ele também é autor do livro Around the Day in Eighty Worlds: Politics of the Pluriverse (Duke University Press, 2021), livro esse que será o centro de toda a entrevista. Além disso, publicou outros trabalhos na mesma linha de pensamento, como o livro The Adventure of Relevance (Palgrave, 2016). Além disso, é co-editor de Speculative Research: The Lure of Possible Futures (Routledge, 2017) e editor-convidado de Isabelle Stengers and the Dramatization of Philosophy (SubStance, 2018) e do Problematizing the Problematic (Theory, Culture \& Society, 2021). Hoje nós vamos discutir seu próximo livro Around the Day in Eighty Worlds: Politics of the Pluriverse que será lançado em 2021. 
Thiago Pinho - Professor Savransky muito obrigado por ter aceitado meu convite.

MARTIN SAVRANSKY - Eu que agradeço pelo convite.

Thiago Pinho - Minha primeira pergunta é simples e direta, ao mesmo tempo que é um pouco pessoal também. Por que pragmatismo? Qual é a importância do pragmatismo em seu novo livro e em sua carreira, em geral?

MARTIN SAVRANSKY - Eu não sei se a pergunta parece simples, não é. Eu tentarei dar uma resposta simples. O pragmatismo não é nada mais do que a arte das consequências, certo? Para mim, ele tem sido criticamente importante. Tanto no alcance do meu interesse filosófico e na maneira como forma e tem formado minha experimentação filosófica. Sem dúvida eu sou extremamente interessado em abstrações e sistemas metafísicos e assim por diante, mas eu sempre estive principalmente interessado em tudo que envolve proposições ${ }^{1}$, ou seja, nas possibilidades e mundos que elas abrem e os tipos de consequências que nós podemos imaginar de certas ideias, perguntas e conceitos. E o pragmatismo é, de certa forma, a intensificação de tudo isso, especialmente na tradição jamesiana, a qual eu estou mais próximo. Ela é a intensificação de uma filosofia, e de uma política, que rejeitam o conforto e as proteções do abstrato, dos princípios universais, afirmando completamente a tarefa arriscada e experimental de aprender a pensar e viver em um mundo sem fundações. O pragmatismo tem sido frequentemente reduzido a uma mera teoria da verdade, nada mais do que uma estranha, inelegante e imerecida "filosofia". Contudo, para James, o tema da verdade é existencial, antes mesmo de ser epistêmico ou cognitivo. O pragmatismo, portanto, é acima de tudo uma arte de viver perigosamente, em um mundo perigoso. Como você pode perceber, todas essas discussões me seguem para onde quer que eu vá (risos).

Thiago PinHo - Você escreve com um estilo mais ensaístico e eu sei que não é uma abordagem aleatória. Existe um significado no fundo, um significado pragmático. Isso é uma coisa que você aprendeu com William James, esse tipo de escrita?

MARTin SAVRANSKY - Sim, além de outras pessoas. Eu presto muita atenção a isso e cuido bastante do meu estilo de escrita. Um amigo meu, que é um poeta, filósofo e ensina literatura em

\footnotetext{
${ }^{1}$ Savransky usa aqui o termo proposição no sentido whiteheadiano, de uma abertura de possibilidades, e não apenas em um sentido analítico, puramente linguístico.
} 
uma escola secundária, tem um termo perspicaz para o que está em jogo aqui. Ele chama de "vontade de estilo". Isso parece, na minha opinião, um termo bem pragmatista: a ideia de que a escrita, até mesmo a escrita filosófica, não apenas expressa alguma coisa, mas ela é em si mesma um acréscimo ao mundo. James disse que filosofias são partes íntimas do universo, formas pelas quais ele pensa a si mesmo. Como tal, a distinção frequentemente traçada entre conteúdo e estilo é uma abstração perigosa. A forma como uma ideia, um sentimento ou uma possibilidade são expressas, é o modo como elas de fato são. $\mathrm{O}$ ponto não é apenas falar algo ou expressar alguma ideia, mas fazer com que ela ressoe de alguma forma, sendo alguma coisa consistente e, portanto, oferecendo um estilo àquela ideia. De certa forma, ambos são indistinguíveis, embora ninguém seja capaz de saber disso lendo apenas textos acadêmicos (risos)!

Mas sim... eu tenho muito cuidado com a forma como escrevo. Eu gosto muito disso na maior parte das vezes. E James tem um modo particular de escrever, principalmente porque muito da sua filosofia era uma filosofia pública, sendo desenvolvida através de palestras que realizava. Ele viajava pelos Estados Unidos e outras partes do mundo palestrando. E muito daquilo que se tornou seus livros são reescritos e edições das palestras que ele ministrou. E, portanto, esses escritos mantêm de uma forma maravilhosa um tipo de oralidade e pluralidade das palestras filosóficas que ele direcionava a um público variado. Elas acabam contribuindo para uma leitura empolgante. Então, de uma certa forma James é também uma influência, já que ele é um escritor talentoso. Essa é uma das razões que me levou a colocar ele no centro do meu livro Around the Day in Eighty Worlds (Duke University Press, 2021), ou seja, não apenas por conta de suas ideias, mas sua forma de expressá-las, de fazer com que os possíveis possam existir. Existe também uma longa relação minha com a literatura e as poéticas da linguagem, de forma mais geral. Eu acredito que não se deve traçar uma rígida distinção entre literatura e filosofia.

Thiago PinHO - Eu estava prestes a falar algo sobre isso, já que algumas vezes seu estilo de escrita parece literatura. E, em geral, nas ciências sociais nós temos tantos estilos de escrita sem graça, chatos.

MARTIN SAVRANSKY - Sim, infelizmente é verdade (risos).

Thiago Pinho - E no seu caso e no de James é um pouco diferente. É alguma coisa mais espontânea e fluida. Mas 
seguindo agora para a próxima pergunta... Nós podemos ver em Isabelle Stengers, umas das referências de sua carreira, uma distinção entre "pensar sobre" e "pensar com". E é bem evidente que não é uma simples diferença gramatical, mas algo mais profundo, como nós podemos ver em seu livro. Você poderia falar sobre isso?

MARTin SAVRANSKY - Sim, claro. E isso segue lado a lado com a pergunta sobre o estilo, não é? Como você estava dizendo, parte do motivo que leva os textos das ciências sociais, e alguns textos filosóficos, possuírem um estilo tão terrível, tem a ver com no que essas disciplinas modernas tem se transformado. Elas têm desenvolvido certos hábitos e padrões de pensamento, ao articular conhecimentos e argumentos sobre vários aspectos da vida social e sobre o mundo, embora nem sempre sejam muito boas quando o assunto é pensar em termos da poética do conhecimento, ou seja, os modos em que o pensamento, a pesquisa e o conhecimento participam no mundo tanto quanto levantam questões sobre o mundo. E é nesse instante em que alguém pode começar a ver a diferença sobre o que você estava sugerindo entre "pensar sobre" e "pensar com". Por exemplo, no caso do meu livro eu nunca pretendi fazer uma exegese do pensamento de James. Eu tenho feito isso em formas mais curtas em artigos e em outros escritos. É claro, essa postura pode ser bem divertida, mas eu nunca tomo isso de forma tão séria como quando eu assumo a tarefa difícil e experimental de "pensar com", que é um pensar ao lado de outros pensadores, mas também ao lado de outras práticas, outras formas de vivência e outras formas de constituir o mundo. A tarefa, em um sentido mais amplo, é recuperar o impulso vital por trás de certa visão filosófica, um certo modo de acreditar no mundo. No meu caso, nesse livro, é o pensamento de William James. É alguma coisa que precisa ser capturada por um ato de imaginação e não simplesmente dissecar uma sequência inteira de passagens vindas de vários livros, a fim de tentar resgatar um sentido abstrato. Claro que a busca pelo sentido dessas passagens é obviamente ainda necessária e crítica, mas nunca pode ser o único propósito. A pergunta, portanto, é sempre uma pergunta pragmática: que tipo de possibilidade a leitura dos textos de James é capaz de produzir e quais consequências podem brotar dela? Nesse livro eu tento pensar com James, assim como pensar com um grande número de outros mundos, embora não com 80, como o título do livro sugere. E isso levanta, na minha opinião, questões profundamente interessantes sobre a natureza da 
realidade e os modos em que nós participamos dela, a maneira como alguns apelos a certas formas de realismo tem se tornado instrumentos políticos de colonização e as maneiras em que nós podemos transformar os modos em que nós habitamos o mundo.

Thiago Pinho - Nós podemos falar mais disso depois, sobre esse seu contato com os estudos decoloniais. Seguindo agora para a próxima pergunta... Eu estava lendo seu livro e logo de início o título me chamou atenção, já que é muito interessante, ao mesmo tempo que soa familiar: Around the day in Eighty Worlds. Você poderia falar um pouco sobre isso?

Martin Savransky - Depende de quem estamos falando. Por um lado, uma das familiaridades, assim como uma das referências disso é Around the World in Eighty Days de Júlio Verne. Ele é um clássico de aventura e um tipo de romance de ficção científica. Um modo estranho, embora adequado, de pensar sobre esse livro é dizer que ele explora o que acontece se nós invertemos a direção, ou seja o sentido, da viagem de Phileas Fogg. Mas o mais importante, e aquele que toca mais meu coração, são os pequenos livros do argentino Julio Cortázar, o qual tem sido um dos meus escritores e pensadores preferidos. Esses pequenos livros são repletos de textos, pequenos ensaios e pedaços de escrita experimental que tem o mesmo título do meu livro Around the Day in Eighty Worlds. Apesar de sua importância, eu não acho que ele tenha sido traduzido para o inglês ainda: $\mathrm{La}$ vuelta al día en ochenta mundos

Thiago PinHo - Provavelmente também não foi traduzido em português. A especulação não é apenas um pequeno detalhe em sua escrita, mas também um método importante para você e o pano de fundo de todo seu livro e carreira. Por que isso?

MARTIN SAVRANSKY - De certa forma, é o outro lado da moeda do pragmatismo, até onde sei. Se o pragmatismo está sempre perguntando qual diferença um conceito faz em resposta a problemas sem os quais eles não têm significado, sem os quais não tem sentido, é também uma coisa que, em minha opinião, está profundamente conectada a uma tentativa de conectar conceitos a possibilidades. É no ato de tecer o pragmatismo e a especulação, naquilo que eu chamo de um certo pragmatismo especulativo, que esse tipo de atividade de experimentação filosófica de "pensar com" o presente ou pensar a partir dos interstícios do presente, a fim de imaginar as coisas de outra forma, torna-se possível para mim. E é isso que distingue o pragmatismo de James daquele de Dewey ou daquele tipo de 
pragmatismo contemporâneo que infelizmente assumiu o controle, em especial na tradição americana, a exemplo de pessoas como Rorty e que tem desmembrado completamente aquela dimensão especulativa do próprio pensamento de James, reduzindo o pragmatismo a um tipo de jogo de linguagem e um nominalismo muito empobrecido.

Thiago Pinho - Você escreveu no começo que existe uma contribuição de Erin Manning e Brian Massumi em seu novo livro. Podemos dizer, então, que existe ali um tipo de Teoria do Afeto por trás de tudo?

Martin SAVRansky - Erin Manning e Brian Massumi são os editores da série em que meu livro foi publicado. Eles foram muito generosos e atenciosos ao acolher esse meu livro (Around the day in Eighty Worlds) na série da Duke University Press, em que eles intitularam Thought in the Act. Eu acredito que por muitos anos eles têm feito um trabalho muito importante em promover e nutrir formas de pensamento pragmáticos e especulativos pelas diversas áreas de humanidades. "Afeto" é um conceito que tem me interessado por muito tempo, mas também é um termo do qual tenho me afastado, de certa forma. Eu acho que a pergunta sobre afeto se tornou interessante especialmente pelo modo como Brian a levantou, que é uma forma de conectar de um modo aparentemente intenso noções metafísicas sobre virtualidade e o virtual. Essa abordagem é reflexo também dos trabalhos de Gilles Deleuze, ao mesmo tempo que se apresenta dentro de um certo empirismo expandido ou de um empirismo radical que poderia nos permitir visualizar e sentir o ingresso do virtual no atual. E, nesse sentido, a observação da passagem do processo de atualização, a partir da teoria dos afetos e seu pano de fundo bem espinosano, foi algo muito produtivo. Apesar disso, todo o debate em torno da teoria afetiva tem saído do controle, onde discussões parecem eternamente confusas entre aquela noção de afeto que Massumi propôs originalmente e a abordagem muito mais diretamente psicológica da ideia de emoção, em que existe uma obsessão pela fronteira entre afeto e linguagem ou afeto e cognição. Eu não acho que esses debates sejam particularmente interessantes. $\mathrm{O}$ que eu quero dizer é que não estou nem um pouco interessado nessas questões. Então, nesse sentido, eu não sou defensor da teoria dos afetos, embora eu apoie o uso que o próprio Brian Massumi originalmente sugeriu, na medida em que se encaixa naquilo que eu chamo do possível, sendo equivalente à noção deleuziana de virtual. 
Thiago Pinho - No segundo capítulo do seu livro você fala de um realismo pluralista. Minha pergunta é: qual seria a diferença entre o seu realismo e outros tipos de realismos hoje em dia?

Martin SAVRansky - Depende de qual tipo de realismo estamos falando.

Thiago Pinho - Por exemplo, o realismo especulativo e assim por diante.

MARTIN SAVRANSKY - Uma diferença principal é que a maior parte dos tipos de realismo, incluindo o realismo especulativo, eu diria, são implicitamente, embora profundamente, preocupados com a questão de onde devemos traçar a linha entre o que é real e o que não é. Cada tipo de realismo tem um modo próprio de traçar essa linha. Claro que eles traçam essa linha diferentemente, mas a preocupação com "o traçar a linha", e ser capaz de dizer que isso é real ou isso é menos real, é um gesto intrínseco a um grande número de projetos realistas. Isso acaba transformando a questão da realidade em uma operação de guerra. O que eu chamo no livro de "realismo pluralista" é antes de mais nada definido pela recusa desse gesto. Eu busco problematizar a própria distinção entre realidade e não realidade, assim como levantar questões pragmáticas que surgem de um tipo de orientação pluralista direcionada ao mundo, além de uma abordagem pluralista direcionada a esse mesmo mundo. Em primeiro lugar, torna o realismo, e portanto a metafísica, um projeto empírico, empirista e coletivo. Contudo, sair para a concretude do mundo não é uma rejeição da metafísica. Muito pelo contrário! É, na verdade, uma tentativa de colocar nossas especulações metafísicas à prova das experiências ao redor do dia em oitenta ou mil mundos (around the day in eithgy or thousand worlds). Ou seja, a ideia é associar metafísica com uma questão ao invés de uma resposta: "O que a realidade é capaz?" Vamos lá fora descobrir o que a realidade é capaz de fazer presente. Ao invés da tendência de traçar aquela linha de forma geral e abstrata, sob a proteção de princípios universais, o realismo pluralista se pergunta o que a realidade é capaz de fazer. Como resultado, ele permanece e se move pelo mundo na tentativa de ouvir as respostas e, nesse sentido, o interesse se baseia na experimentação com as consequências dessas respostas e o que elas tornam possível, sendo aí onde a atitude pragmática entra em ação. Se fantasmas são reais em alguns lugares, em certas circunstâncias, como aconteceu, por exemplo, na esteira do Grande Terremoto e Tsunami no Leste do Japão, logo possivelmente um edifício metafísico inteiro, além 
de toda uma construção da vida pública, precisa ser revisado no despertar dessa descoberta, no despertar dessa realidade. E isso é, de certa forma, um experimento que o livro tenta sugerir com o nome de "realismo pluralista".

Thiago Pinho - Eu estava pensando sobre isso ultimamente. Você acha que fazer parte do universo das ciências sociais ajuda os seus escritos a escaparem da abstração? Ou seja, o debate sobre realismo na filosofia é talvez diferente das ciências sociais... talvez para nós seja alguma coisa mais concreta, material. A gente precisa enxergar, e reconhecer, quer gostemos ou não, outros tipos de interações, outros tipos de ontologias. Provavelmente para um filósofo essa exigência talvez não seja tão presente como nas ciências sociais. O que você acha?

MARTIN SAVRANSKY - É verdade que eu tenho um pano de fundo interdisciplinar, mas eu nunca fui necessariamente um bom cientista social (risos). Talvez eu caracterizaria isso que você disse de forma inversa. Então, eu acho que estar em contato próximo com as ciências sociais torna-se importante por conta das premissas empiristas com as quais concordo e que afirmo. $\mathrm{Na}$ minha opinião, alguém não pode escrever um livro que pretende levar James a sério da mesma maneira que alguém escreve um livro sobre realismo especulativo, porque, na verdade, as realidades concretas e experiências importam muito e nenhum argumento do tipo "o gato está sobre o tapete" vai ser capaz de dar conta da situação. Como James disse uma vez, a "coisa em si mesma" é incrivelmente difícil de capturar. Mas isso não significa que as coisas estão sempre "para nós", no típico pesadelo correlacionista. A proposta é, ao contrário, dizer que as coisas nunca são algo por conta própria, e que nem nós e nem elas estão sozinhas no mundo.

Thiago Pinho - Ao longo de todo o livro você usa um termo muito interessante e que provavelmente guarda uma forte influência de seus estudos decoloniais. $\mathrm{O}$ que seria aquilo que você chama de moderna monificação do mundo? O que você quer dizer com isso?

MARTIN SAVRANSKY - Monificação é um termo não muito bonito que eu criei. Monificação vem da ideia de monismo, sendo a postura filosófica que considera a unidade como algo mais fundamental do que a pluralidade e a diferença. E uma das coisas que eu sugiro no livro é o quanto o monismo não é apenas uma postura filosófica gratuita, que alguém pode escolher ocupar. James já deixou claro, acho que em 1907, quando ele 
escreveu as palestras sobre pragmatismo: o mundo está constantemente sendo unificado e pluralizado graças às várias práticas, sistemas, comunicações, formas de influência e causalidades que são construídas dentro dele e através das quais é composto. Se nós pensamos no monismo naqueles termos, as histórias entrelaçadas do capitalismo, do extrativismo e do colonialismo têm sido histórias de uma monificação e de um processo que torna o mundo um globo. Pense nos modos em que o projeto moderno, enquanto um projeto imperial e colonial, tem sido fundamentalmente um projeto de homogeneização da diferença, assim como uma devastação das diferenças ao redor do mundo. A própria composição do mundo (e mundos) enquanto um globo que nos envia desastres da globalização, e não menos importante a pandemia que nós estamos agora, não é apenas alcançado conceitualmente, mas também praticamente, materialmente e empiricamente através de processos de homogeneização, além de processos de monificação.

Thiago Pinho - E isso nos leva para a próxima pergunta... Você é um pensador decolonial, como nós podemos observar em seu livro e em outros escritos também. O tema da decolonialidade não é só um detalhe em sua carreira, mas também atravessa vários temas discutidos em seus textos, assim como se entrelaça com o seu próprio pano de fundo pragmático. Como você definiria sua abordagem decolonial nesse novo livro? Quais as diferenças frente a outras abordagens?

MARTIN SAVRANSKY - Uma das coisas que eu estava interessado nesse livro era estabelecer uma conversa com diferentes autores, com diferentes disciplinas e com diferentes grupos de debates, mas um deles é, de fato, acadêmicos e pensadores pós-coloniais e decoloniais. Nesse sentido, uma das expectativas foi precisamente fazer uma contribuição para aqueles debates, ao sugerir que o pensamento decolonial pode, mas não precisa necessariamente, fundamentar-se naqueles mesmos tipos de fontes, suposições e pressuposições filosóficas que ele tende a se fundamentar. Existe uma certa homogeneidade filosófica quando se trata dos modos em que o pensamento decolonial é habitualmente costurado e articulado (com algumas exceções pontuais, como, por exemplo, no trabalho de pensadores afrocaribenhos, tais como Aimé Césaire ou Édourard Glissant e, com certeza, e mais recentemente, a abordagem antropológica do brasileiro Eduardo Viveiros de Castro, e que são as mais interessantes, na minha opinião). Um dos gestos que algumas 
tradições do pensamento decolonial tende a mobilizar é um tipo de antirrealismo direcionado contra o essencialismo dos modernos. A crítica decolonial tende a ser aquela que questiona a ingênua objetividade e o essencialismo que segue ao lado dos projetos orientalistas, colonialistas e imperialistas. Eles fazem isso ao apelarem para uma crítica antirrealista que problematizaria a noção de realidade como um todo, a fim de questionar os apelos do realismo clássico que o projeto moderno estabeleceu. Ao fazer isso, eles tornam visível o caráter completamente provincial, chamada pelos modernos de realidade, ao sugerirem que o conhecimento moderno é sempre parcial e incompleto, produto de uma cultura particular, e que existem outros modos de conhecer o mundo. Eu os entendo completamente, e apoio esse esforço, mas eu também penso que muitas possibilidades se perdem nesse gesto antirrealista, em que o sentimento de realidade é subordinado a questões de epistemologia. Apesar do projeto colonial, outros mundos e outras realidades insistem e persistem nas ruínas que os modernos têm deixado para trás. Como nós podemos aprender a afirmar a realidade no plural, ao invés de mantê-la à distância? Uma das coisas que eu tento fazer, a partir de uma conexão com o trabalho de William James, foi dizer que, na verdade, talvez nós possamos articular formas de pensamento decolonial a partir de um pano de fundo empirista, experimental, pragmático e filosófico, ao invés de um tipo de linguagem centrada em uma posição pós-estruturalista e antirrealista.

Thiago PinHo - Debates epistemológicos podem acabar sendo um grande obstáculo, principalmente quando precisamos manter o compromisso com o mundo ao redor. Para você, nós temos que superar as limitações dos infinitos debates epistemológicos que ainda circulam pelas universidades, eu estou certo? Temos de seguir por uma outra direção... talvez um percurso mais ontológico seria muito melhor.

Martin Savransky - Você se refere ao pensamento póscolonial e decolonial, não é? Eu acho que esse é uma das consequências que brota do antirrealismo do pensamento decolonial. Existe sempre uma suposição, uma que é muito desconfortável e extraordinariamente moderna e kantiana, de que não podemos falar nada a respeito da realidade em si mesma. E o que quer que seja dito sobre a realidade tem que ser acompanhada por um processo de mediação epistêmica. Isso significa, portanto, que a arena da política se mistura com um tipo de política epistêmica. Nesse sentido, eu sou muito mais 
próximo dos realistas especulativos e sua recusa do "correlacionismo", que infelizmente atravessa muito do pensamento decolonial. Como eu gosto de dizer, não existe política do conhecimento sem uma política da realidade. E isso implica, como você sugeriu bem, nos movermos além de debates epistemológicos. Claro que isso não significa destruir completamente as questões sobre conhecimento e epistemologia, até porque algumas vezes questões sobre conhecimento estão em jogo, mas é preciso se mover além da suposição de que é sempre um assunto de conhecimento que está em jogo, sendo esse o registro principal em que alguns modelos decoloniais de pensamento se articulam e tecem a si mesmos. Eu não compartilho dessa visão nem um pouco. Eu acho que existe muito mais na política de decolonialidade do que questões sobre epistemologia. A realidade, como James diria, se assemelha a si mesma, no plural.

Thiago Pinho - E isso é interessante especialmente porque nas ciências sociais nós estamos presos nesse pano de fundo kantiano a todo momento. Existe uma inclinação, quase natural, por debates envolvendo linguagem, poder, cultura, estrutura, sistema, etc. E a ontologia se torna algo distante que nós não podemos nem sequer mencionar, já que é vista como só um produto ideológico qualquer. E isso é algo bem problemático, especialmente nos dias atuais que pedem por um compromisso mais fiel com a própria realidade.

MARTIN SAVRANSKY - Eu acho que as ciências sociais são profundamente kantianas.

Thiago Pinho - Sim (risos)... esse é o problema. Especialmente hoje, por exemplo, quando nós tentamos seguir o caminho vitalista de autores como Bruno Latour e Donna Haraway, ao conectar não apenas humanos, mas animais, objetos, etc. Algumas vezes é um pouco difícil nas ciências sociais, principalmente porque nós não estamos acostumados a isso ainda. Como eu posso falar de objetos? Ou como eu posso falar de animais? Tudo isso é estranho se estamos presos em um pano de fundo kantiano a todo momento.

MARTIN SAVRANSKY - Com certeza. É nesse sentido que eu penso precisamente que as pessoas mencionadas por você, como Bruno Latour e Donna Haraway, mas também outras como Vinciane Despret e Isabelle Stengers, têm sido incrivelmente inteligentes ao articular os modos em que podemos levar mais a sério as relações sociais. Não existe sociedade sem objetos: o 
social é sempre mais-que-humano. "Nós nunca fomos humanos", diz Haraway. E ela está certa na medida em que não existe tal coisa como o humano separado da multiplicidade de não humanos, sejam eles bactérias, deuses ou bilhões de outros entes. Nós não comporíamos e viveríamos na vida pública, do modo como nós fazemos, sem a existência de portas, por exemplo, ou sem os milhares de organismos não-humanos com os quais nós habitamos e que, por sua vez, nos habitam. Portanto, essa suposição de que os objetos estão apenas no pano de fundo, "para nós", fazendo nada, é profundamente questionável em termos filosóficos, por conta dessa tradição kantiana, mas também bastante incoerente em termos empíricos. É quase como se os cientistas sociais fossem treinados, de um jeito sistemático, para negligenciarem e ignorarem mais da metade do que está acontecendo em seus campos de pesquisa, ou seja, no próprio mundo social.

Thiago Pinho - Especialmente, talvez, em termos políticos, porque esse pano de fundo kantiano é conveniente para nós, já que podemos controlar tudo - ao menos essa é a impressão que temos. Se cada centímetro da realidade nada mais é do que um simples epifenômeno de relações de poder, ou se tudo é apenas um desdobramento de jogos de linguagem, isso cria a impressão de que finalmente descobrimos as causas, os fundamentos, os culpados, além de recuperar uma sensação de controle. Por isso que quando nós vamos para esse tipo diferente de ontologia, como essa que você propõe, acaba sendo um pouco assustador para o sociólogo. Por isso não conseguimos ir além do kantismo, desse transcendentalismo, em especial porque é tão conveniente e acalentador nesse pano de fundo kantiano.

MARTIN SAVRANSKY - E isso é parcialmente também um efeito do que Whitehead teria chamado de "mentes na fenda". O que você mencionou é parte de um treinamento disciplinar de décadas. E, claro, carrega aspectos muito convenientes: tudo acaba sendo trazido de volta para o terreno em que cientistas sociais se sentem confortáveis, ao submeter tudo a um tipo de explicação que eles sabem como articular. Essa postura é algo de venenoso, mas é isso que estudantes de sociologia, por exemplo, aprendem desde o primeiro momento. E por isso cientistas sociais se tornam muito bons falando de linguagem, conhecimento, ideologia, relações de poder, etc. E, de fato, como você disse, eles enxergam o outro lado como um espaço assustador. Mas quando você pensa sobre isso com olhares menos tendenciosos, todas essas suposições sobre o poder da 
linguagem, e a própria epistemologia, são extraordinariamente contraintuitivas. É muito óbvio o quanto existem coisas materiais nesse mundo que fazem uma diferença prática e vital. Na verdade, alguém precisa trabalhar muito duro para fazer com que essas coisas desapareçam. Porém, aqui estamos nós e são essas as ciências sociais que estão disponíveis no momento.

Thiago PInHO - Hoje é comum observar, seja na TV ou nas próprias redes sociais, grupos questionando a redondeza da terra, o aquecimento global, a eficácia das vacinas, e assim por diante. Diante de tudo o que conversamos até agora, como você acha que nós podemos reconhecer o realismo desses fatos, assim como manter um compromisso com a ciência e seus achados, mas sem cair necessariamente em uma monificação do mundo?

MARTIN SAVRANSKY - Eu acho que essa é uma pergunta muito boa e interessante, principalmente por ser um tipo de pergunta que normalmente alguém que embarca em um projeto pluralista precisa lidar. É possível perceber os modos como certas consequências do racionalismo moderno, e certas formas modernas de realismo, tem, de fato, sido vitais para a construção de um projeto moderno da vida pública. O momento em que alguém começa a pluralizar o real e problematizar a suposição de uma unidade, prestando atenção nas diferenças de forma séria, essas questões emergem ao lado de um sentimento de medo. Muitos acreditam que as construções da vida pública que nós conhecemos devem ser acolhidas a qualquer preço, caso contrário, caso suas premissas sejam questionadas, esse tipo de postura vem acompanhada da acusação de "relativismo". Eu não acho que exista uma receita geral, por assim dizer, para ser capaz de distinguir o que constitui a construção de outro mundo dentro desse mundo, um mundo que na minha opinião nós devemos levar de forma séria e aprender a pensar com ele, e, por outro lado, o que constitui uma perigosa teoria da conspiração. Mas eu penso que existe um modo mais amplo para começar essa abordagem, principalmente pelo fato de que muitos desses grupos estão bastante presentes no cenário atual, como, por exemplo, os terraplanistas, o crescente número de teorias da conspiração, o movimento anti vacina, o surgimento do que as pessoas chamam de fake news, pós-verdade, etc. Eles se articulam em torno de um mesmo plano cosmológico, e em torno do mesmo critério comprobatório, como os próprios modernos. Na verdade, eles são modernos, o que normalmente é ignorado naqueles debates públicos em torno desse fenômeno. O que caracteriza esses grupos, essas conspirações, não é tanto o fato de 
que esses grupos compreendem as coisas de forma errada, falsa e perigosa, vivendo suas vidas em razão dessa forma distorcida. Nós tendemos a falar deles como se fossem pessoas facilmente manipuláveis e levadas a acreditar em teorias da conspiração. A meta, portanto, seria fazê-los entender quais são os critérios relevantes de evidência, quais as fontes oficiais que alguém deve seguir e como distinguir entre fontes científicas de informação e aquelas que são invalidadas. Isso significa que o que está em jogo é um problema de crença, é um problema de confiar em pessoas e ideias erradas. Na minha opinião, o problema é o contrário. $\mathrm{O}$ ponto central não é que existe uma confiança nas pessoas e ideias erradas, mas o que existe é uma profunda desconfiança no mundo. Existe uma falta de crença no mundo e isso é notável por duas razões. A primeira razão é que é possível caracterizar esses grupos como sendo movimentos que não possuem um outro projeto de vida coletiva. Isso é o que distingue, por exemplo, uma pessoa ou movimento anti vacina de uma testemunha de Jeová que não aceitaria transfusões de sangue, já que seus princípios são baseados em estruturas teológicas e religiosas. Essa á uma diferença entre esses dois grupos: as testemunhas de Jeová articulam um modo de vida coletivo que surge de um entendimento compartilhado de mundo, assim os modos compartilhados de habitá-lo. Os agrupamentos anti vacina, se é que existe algo assim, não constroem um mundo para habitar, sendo muito mais um projeto puramente niilista. E, segundo, isso sugere que esses são projetos puramente negativos, fundamentados no crescimento de uma patológica intensificação de uma atitude que é profundamente moderna, uma atitude de desconfiança. Nós fomos ensinados que para ser inteligente e racional a ciência precisa ter padrões incrivelmente elevados de evidência e, portanto, ser capaz de desconfiar dos seus próprios sentidos. Não fomos nós, os modernos, ensinados que racionalidade e inteligência são associadas com ceticismo, com a desconfiança das aparências, e que essa atitude de não se deixar enganar com as aparências? Não é essa precisamente uma das virtudes associadas com o que as pessoas chamam de "método científico"? Nós também não temos coroado as meditações de Descartes, onde ele sustenta que a forma de dúvida radical o levou a duvidar da existência do próprio corpo, ao mesmo tempo que considerando isso um exemplo do racionalismo moderno?

Nós coroamos Descartes e suas meditações como o ápice da racionalidade moderna. Eu sempre quis apresentar suas 
meditações sobre filosofia como um drama de um homem paranoico que perdeu seu rumo e que tem perdido completo contato com o mundo. Alguém que nem sequer pode confiar em seu próprio corpo, na minha opinião, não é um bom exemplo de racionalidade, mas é nisso que a modernidade se baseia. Parece que, em grande medida, essas teorias conspiratórias são partes essenciais do mundo moderno. Eles não são apenas o outro, mas parte de nós mesmos e isso transforma radicalmente o problema. Porque o ponto principal não é mais de prevenir as pessoas de seguir falsos profetas. Na verdade, o ponto é de como cultivar confiança.

THiago PinHO - E algumas vezes você pode ver isso nas ciências sociais também aqui no Brasil. A ideia, por exemplo, de que alguém é visto como uma pessoa esperta se é capaz de mostrar as contradições do seu objeto de estudo, podendo ser este uma outra pessoa, ideia ou instituição. Ou seja, se você é capaz de puxar o tapete. Essa atitude lembra muito aquilo que alguns pensadores chamam de ressentimento epistemológico. Nós estamos o tempo todo nesse movimento. Jamais construindo, mas sempre cutucando, destruindo ou mostrando contradições.

MARTIN SAVRANSKY - Isso é o que em meu primeiro livro eu chamei de Ética do Estranhamento. Aquele livro era sobre o processo de conhecimento não apenas nas ciências sociais, mas, como você disse, isso se aplica àquela ideia de que a inteligência de alguém procede da suposição de que as coisas nunca são o que elas parecem ser. E a tarefa da crítica, a tarefa das faculdades críticas de alguém, seria supostamente ultrapassar as aparências, ganhando acesso a algum reino mais real de causas, fatores, poderes, e assim por diante. E eu acho que esse é o coração de muitas ciências sociais, mas também o coração da cultura moderna. E esse é um dos grandes venenos em que nós atualmente ingerimos.

Thiago Pinho - Você disse em seu livro, em algum momento, que diferentes mundos não estão em completo isolamento. Portanto, como eles se tocam? Estaríamos falando aqui do conceito de experiência pura de William James, enquanto uma conexão entre mundos diferentes? O que eu quero dizer é... como eu posso produzir um contato com outros mundos ou outros tipos de ontologias?

MARTIN SAVRANSKY - Eles não estão em completo isolamento tanto por razões empíricas, quanto por razões filosóficas. Esse é o motivo de eu frequentemente falar deles no livro enquanto 
"outros mundos nesse mundo". E eu continuo usando essa frase porque é o modo de James de enfrentar esse eterno problema metafísico sobre o uno e o múltiplo... se o mundo é um ou o mundo são muitos, etc. A resposta dada por ele, e de um modo bem-humorado e pragmático, é que a resposta seja "ambos". São "muitos", de certa forma, e ao mesmo tempo "um", de outras formas e na medida em que é um. Por exemplo, padrões climatológicos se distribuem diferentemente, mas também através do planeta de formas que estão profundamente interconectados. Contudo, dizer que a multiplicidade de mundo está conectada, não significa dizer, de forma nenhuma, que a mudança climática nos conduz a uma grande e homogênea humanidade. Isso significa que existem outros modos pelos quais o mundo está conectado, assim como existem outros modos pelos quais o mundo está desconectado. A importância disso se fundamenta, eu acredito, no fato de que permite nos afastarmos de um dos riscos que surge de outras formas de pluralismo, que é o perigo do solipsismo, o que nos leva novamente para a areia movediça kantiana. A imagem seria baseada na figura de alguém que é parte de um mundo ou parte de uma cultura ou parte de uma sociedade e, por definição, seria incapaz de escapar dela. E, portanto, os mundos, nesse sentido, não podem se tocar porque não existe um mundo exterior que possibilitaria a existência de tal encontro. Isso é um argumento teórico tentador, mas é empiricamente falso. E uma das coisas que eu tentei mostrar no livro, são os modos como as pessoas realmente aprendem a participar e a se tornar parte de mundos que eram distantes para elas no passado: a história de Tanva Lurhmann sobre os grupos de evangélicos nos Estados Unidos que precisam aprender praticamente e laboriosamente como transformar Deus em algo real, como uma presença intima em suas vidas, ao usar todos os tipos de práticas de reza, leitura, etc. Também podemos pensar na história de Edith Turner, a mulher do famoso antropólogo Victor Turner, que retornou para a Zâmbia para estudar práticas de cura, conseguindo não apenas participar daquelas práticas, mas também ver com seus próprios olhos a emergência de um espírito que surge das costas de uma mulher. Portanto, as fronteiras entre os mundos são claramente porosas. Para James, eu insisto nisso, o mundo é tanto uno quanto vários, em processo e sem finalização.

Thiago PinHo - E provavelmente isso tem a ver com aquilo que você chamou da decolonização do plural, um tema que você discute muito em seu livro. Ou seja, essa situação onde eu preciso 
evitar o solipsismo, de certa forma. Nós não podemos cair nisso.

Então... acredito que encerramos. Foi ótimo. Professor Savransky, muito obrigado novamente pelo seu tempo.

MARTIN SAVRANSKY - Eu que agradeço pelas perguntas.

\section{Referências bibliográficas}

SAVRANSKY, Martin. 2021. Around the Day in Eighty Worlds: Politics of the Pluriverse. Durham, NC: Duke University Press. 2021. "Problematizing the Problematic" [organização de dossiê]. Theory, Culture E Society 38(1).

2018. "Isabelle Stengers and the Dramatization of Philosophy" [organização de dossiê]. SubStance 47(1).

2016. The Adventure of Relevance: An Ethics of Social Enquiry, with a foreword by Isabelle Stengers. London: Palgrave Macmillan.

WILKIE Alex; SAVRANSKY, Martin; ROSENGARTEN, Marsha (Eds.). 2017. Speculative Research: The Lure of Possible Futures. London: Routledge.

Enviado: 27 de janeiro de 2021

Aceito: 3 de fevereiro de 2021 